\title{
Sensitivity and Resistivity Pattern of some commonly used Antibiotics against Urinary Tract Infection (UTI) among elderly individuals from Garhwal Region of Uttarakhand, India
}

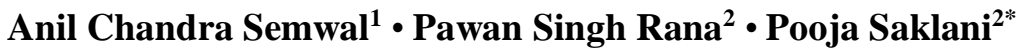 \\ ${ }^{1}$ Department of Microbiology, Veer Chandra Singh Garhwali Govt. Medical College Srinagar Garhwal \\ Uttarakhand-246174 \\ ${ }^{2}$ Department of Biotechnology, HNB Garhwal University (A Central University), Srinagar Garhwal, Uttarakhand \\ *Corresponding Author: poojasaklani@ rediffmail.com
}

Received: 8.8.2021; Revised: 3.9.2021; Accepted: 29.11.2021

(C) Society for Himalayan Action Research and Development

\begin{abstract}
Urinary Tract Infection is a very common kind of microbial infection (mainly bacterial) that affects all the age groups. A high UTI infection rate has been reported in 51 and above aged population beside it's highly prevalent in sexually active population. In recent times most of the commonly used antibiotics has reported being less effective against UTI. In this light a retrospective study was designed to understand the resistivity and sensitivity pattern of bacterial population against commonly used antibiotics in 51 plus population of Garhwal region. Urine samples from individuals were collected in sterile bottles. Bacterial cultures from these samples were obtained, pure cultures were isolated and identified using their characteristic biochemical tests. Resistivity and sensitivity pattern of antibiotics were assessed by agar well method. A high infection rate reported in males as compared to females. $E$. coli was found main infective agent in most of the samples followed by S. aureus and CoNS. High resistance level was observed against most of the antibiotics generally used while meager of such antibiotics found sensitive to isolates. The high resistivity shown by bacterial population to antibiotic can be attributed to the irrational use and this highlights the need of developing novel antibiotics. The study provides a baseline data for the UTI sensitive elderly population of Garhwal region. This will also help the state health department in making strategies to contain the infection among elderly people which sometimes becomes life-threatening in the remote hilly areas of this region.
\end{abstract}

Key words: UTI, Antibiotics, Bacteria, Resistance, Garhwal, elderly population

\section{Introduction}

In clinical practices, Urinary Tract Infections (UTIs) represents one of the most common diseases all over the world, affecting people of all ages from the neonate to the geriatric age group (Farzana et. al., 2013; Jamil et. al., 2014). In most of the part of the world, because of the lack of proper medical facility to deal with the infection, the condition gets grimmer and sometimes is the reason of the development of new drug resistant strains which is now a policy matter of concern for the developed countries. In recent years, extensive utilization of antibiotics without any medical prescription and because of the shortfall of the antibiotic course has resulted in cumulatively increased incidence of drug resistance among the uropathogens. The UTIs is one of the major contributors to total antibiotic use and resistance (Manikandan et. al., 2011). The present study has been set as surveillance of the Garhwal region of Uttarakhand Province of India. This surveillance study; however, based on the data as generated by the pathologies and clinical practices prevailing in the region.

Urinary tract infection (UTI) is the most common bacterial infection in the older patient 
population, and Escherichia coli is the most common uropathogenic community dwelling people older than 65 years (Barnett and Stephens, 1997). The spectrum of UTI ranges from a mild self-limiting illness to severe sepsis, with a mortality rate of $20-40 \%$ (Gharbi et al., 2019). The incidence of sepsis and its associated mortality increases disproportionately with age, and UTI in men is more likely to be severe. Both sexes develop UTI in old age, with a female to male ratio of 2:1 in patients older than 70 years, compared with the overwhelming UTI susceptibility of females in younger populations, with a 50:1 ratio (Angus et al., 2001). The diagnosis of UTI in older patients can be problematic, as these patients are less likely to present with a typical clinical history and localized urinary symptoms compared with younger patients (Rowe and Mehta, 2013). The rising incidence of asymptomatic bacteriuria in older adults is also contributing to further diagnostic difficulty ( $>20 \%$ of women aged $\geq 65$ years compared with $<5 \%$ in younger women), which results in probable over-diagnosis of UTI and unnecessary treatment (Mody and Mehta, 2014). UTI is the second most common diagnosis for which empirical antibiotics are prescribed in both primary and secondary care, with more than $50 \%$ of the antibiotics prescribed for a suspected UTI in older adults being considered unnecessary (Crnich et al., 2017; Nace et al., 2014; PHE, 2016).
The UTI is now a very common phenomenon among the age group of 51 and above in this region. This led us to design present study as the use of common antibiotics that are generally given to patients attending the VCSG Medical College and HNB Base Hospital Srikot Srinagar Garhwal, Uttrakhand, India, are also used in the treatment of UTI. Assessment of the effects of such irrational use of antibiotics on UTI is focal point of this study.

\section{Materials and Methods}

A retrospective population-based cohort study was conducted in Uttarakhand on the patients attending HNB Base Hospital Srikot, Srinagar (Garhwal), Uttarakhand, India, between November 2013 and Jan 2016. Since this study was designed with a Retrospective approach, any approval of any Ethical Committee was not required. Urine samples of the patients were collected in pre-sterilized containers. The isolation, identification and antibiotic sensitivity test of the Uropathogens in the collected samples was done in a similar manner as our previous report (Semwal et. al., 2017).

\section{Results}

A total of 218 samples were collected from the patients in the age group of 51 and above, of these 131 were males $(60.09 \%)$ and 87 were Females $(39.91 \%)$. The Table 1 shows the data of older (51 year and above age group), 83 males and 50 females were found non-infected, 
Table 1 Description of infected and non-infected individuals older

$\begin{array}{lll}\text { Description of Individuals } & \text { Male } & \text { Female } \\ \text { Infected Samples (Non infected Individuals) } & 83 & 50 \\ \text { Non-infected Samples (Infected Individuals) } & 48 & 37 \\ \text { Total } & 131 & 87 \\ \% \text { of Infected individual } & 22.01 & 16.97\end{array}$

The microbes observed in infected samples are presented in Table 2. Most of the samples were found infected by E. coli followed by the Acinetobacter sp. in Gram Negative Bacillus (GNB) group, while in GPC group CoNS followed by Enterococcussp. found most infectious micro-organism. Among fungus Candidaalbicans was primary causative agent.

Table 2 Pathogens present in infected samples

\begin{tabular}{lll}
\hline Microbes as Observed & Male & Female \\
\hline Mixed Growth & 2 & 2 \\
\hline Gram Negative Bacillus (GNB) & 20 & 19 \\
\hline Escherichia coli & 0 & 1 \\
Klebsiella sp. & 2 & 1 \\
Citrobactersp. & 1 & 0 \\
Morgenellasp. & 3 & 1 \\
Acinetobacter sp. & 2 & 0 \\
Pseudomonas aeruginosa & & \\
\hline Gram Positive Cocci (GPC) & 6 & 0 \\
\hline Staphylococcus aureus & 8 & 4 \\
CoNS (CogulaseNeagtive Staphylococci) & 1 & 0 \\
Beta Haemolytic Streptococci & 2 & 6 \\
Enterococcus sp. & \multicolumn{2}{c}{} \\
\hline Fungus & \multicolumn{2}{l}{} \\
\hline Candida albicans & $\mathbf{4 8}$ & $\mathbf{3 7}$ \\
\hline Total & & \\
\hline
\end{tabular}

Most of the individuals were found infected by Gram Negative Bacillus (GNB's) bacteria (28 males and 22 female), followed by Gram Positive Cocci (GPC's) bacteria while a negligible portion (1 male and 3 females) of the collected samples was found infected by fungus i.e. Candida sp. (Table 3)

The overall sensitivity and resistant pattern of 33 drugs that are commonly used in treatment of UTI is shown in Table 4. Out of the 33, the pathogens were found resistant to the first 16 (Table 4) while to next 16 drugs they were showing sensitivity. Piperacillin showed an intermediate effect while the rest two 
Colistin and Ploymixin B did not show any activity in any sample. Overall Sensitivity ranged from 19.3\% to $1.4 \%$ while the range of resistance was between $18.3 \%-0.5 \%$.

Table 3 Group of Pathogens found Present in Infected Samples

Microbes as Observed Male $\quad$ Female

\begin{tabular}{lll}
\hline GNB & 28 & 22 \\
GPC & 17 & 10 \\
Candida & 1 & 3 \\
\hline Total & $\mathbf{4 6}$ & $\mathbf{3 5}$
\end{tabular}

Table 4 Overall Sensitivity and Resistance Pattern of Commonly used Antibiotics in Case of UTI

\begin{tabular}{|c|c|c|c|c|c|c|c|c|}
\hline \multirow[t]{2}{*}{ Sr. No. } & \multirow[t]{2}{*}{ Drugs } & \multicolumn{2}{|c|}{ Profile } & \multicolumn{3}{|c|}{$\%$ Value } & \multirow[b]{2}{*}{$\mathbf{S}$} & \multirow[b]{2}{*}{ NR } \\
\hline & & $\mathbf{R}$ & $\mathbf{S}$ & NR & Total & $\mathbf{R}$ & & \\
\hline 1. & Cefotaxime & 40 & 10 & 168 & 218 & 18.3 & 4.6 & 77.1 \\
\hline 2. & Ciprofloxacin & 38 & 17 & 163 & 218 & 17.4 & 7.8 & 74.8 \\
\hline 3. & Amoxicillin-clavulanic acid & 37 & 14 & 167 & 218 & 17 & 6.4 & 76.6 \\
\hline 4. & Cefipime & 31 & 8 & 179 & 218 & 14.2 & 3.7 & 82.1 \\
\hline 5. & Co-trimoxazole & 29 & 22 & 167 & 218 & 13.3 & 10.1 & 76.6 \\
\hline 6. & Ticarcillin Clavulanic Acid & 28 & 6 & 184 & 218 & 12.8 & 2.8 & 84.4 \\
\hline 7. & Cefuroxime & 26 & 11 & 181 & 218 & 11.9 & 5 & 83 \\
\hline 8. & Aztreonam & 24 & 10 & 184 & 218 & 11 & 4.6 & 84.4 \\
\hline 9. & Cefazolin & 23 & 10 & 185 & 218 & 10.6 & 4.6 & 84.9 \\
\hline 10. & Ampicillin & 21 & 2 & 195 & 218 & 9.6 & 0.9 & 89.4 \\
\hline 11. & Erythromycin & 15 & 12 & 191 & 218 & 6.9 & 5.5 & 87.6 \\
\hline 12. & Clindamycin & 11 & 8 & 199 & 218 & 5 & 3.7 & 91.3 \\
\hline 13. & Ceftazidime & 7 & 2 & 209 & 218 & 3.2 & 0.9 & 95.9 \\
\hline 14. & Tobramycin & 2 & 1 & 215 & 218 & 0.9 & 0.5 & 98.6 \\
\hline 15. & Oxacillin/Cephoxitin & 0 & 3 & 215 & 218 & 0 & 1.4 & 98.6 \\
\hline 16. & Tetracycline & 0 & 1 & 217 & 218 & 0 & 0.5 & 99.5 \\
\hline 17. & Amikacin & 11 & 42 & 165 & 218 & 5 & 19.3 & 74.8 \\
\hline 18. & Nitrofurantoin & 6 & 39 & 173 & 218 & 2.8 & 18.3 & 78.9 \\
\hline 19. & Gentamycin & 29 & 36 & 153 & 218 & 13.3 & 16.5 & 70.2 \\
\hline 20. & Piperacillin tazobactum & 7 & 32 & 179 & 218 & 3.2 & 14.7 & 82.1 \\
\hline 21. & CefoperazoneSulbactum & 7 & 30 & 181 & 218 & 3.2 & 13.8 & 83 \\
\hline 22. & Meropenem & 14 & 23 & 181 & 218 & 6.4 & 10.6 & 83 \\
\hline 23. & Linezolid & 2 & 20 & 196 & 218 & 0.9 & 9.2 & 89.9 \\
\hline 24. & Vancomycin & 0 & 19 & 199 & 218 & 0 & 8.7 & 91.3 \\
\hline 25. & Chloramphenicol & 5 & 15 & 198 & 218 & 2.3 & 7.3 & 90.4 \\
\hline 26. & Rifampicin & 3 & 14 & 201 & 218 & 1.4 & 6.4 & 92.2 \\
\hline 27. & Teicoplanin & 8 & 11 & 199 & 218 & 3.7 & 5 & 91.3 \\
\hline 28. & Penicillin & 3 & 4 & 211 & 218 & 1.4 & 1.8 & 96.8 \\
\hline 29. & Netilmicin & 1 & 3 & 214 & 218 & 0.5 & 1.4 & 98.2 \\
\hline 30. & Azythromycin & 1 & 3 & 214 & 218 & 0.5 & 1.4 & 98.2 \\
\hline 31. & Piperacillin & 1 & 1 & 216 & 218 & 0.5 & 0.5 & 99.1 \\
\hline 32. & Colistin & 0 & 0 & 218 & 218 & 0 & 0 & 100 \\
\hline 33. & Polymixin B & 0 & 0 & 218 & 218 & 0 & 0 & 100 \\
\hline
\end{tabular}

(R-Resistant, S-Sensitive, NR-No Response) 
Further, the drugs were screened separately on the basis of (i) Sensitivity and (ii) resistance shown by microbe towards them. Table 5 is showing the sensitivity profile of the drugs to which UTI causing bacteria were sensitive. Although 14 drugs were showing sensitivity (Table 4) but only those showing sensitivity above $19 \%$ were considered as sensitive drugs. Amikacin was most sensitive with total sensitivity value of about $19.3 \%$ followed by Nitrofurantoin 18.3\%, Gentamycin having sensitivity value of $16.5 \%$ and Piperacillintazobactum with $14.7 \%$.

Table 5 Sensitive Drugs for UTI

\begin{tabular}{llllllll}
\hline \multirow{2}{*}{ Sr. No. } & Drugs & \multicolumn{3}{c}{ Profile } & \multicolumn{4}{c}{ \%Value } \\
\cline { 3 - 8 } & & $\mathbf{R}$ & $\mathbf{S}$ & $\mathbf{N R}$ & $\mathbf{R}$ & $\mathbf{S}$ & NR \\
\hline 1. & Amikacin & 11 & 42 & 165 & 5 & 19.3 & 74.8 \\
2. & Nitrofurantoin & 6 & 39 & 173 & 2.8 & 18.3 & 78.9 \\
3. & Gentamycin & 29 & 36 & 153 & 13.3 & 16.5 & 70.2 \\
4. & Piperacillin tazobactum & 7 & 32 & 179 & 3.2 & 14.7 & 82.1 \\
5. & Cefoperazonesulbactum & 7 & 30 & 181 & 3.2 & 13.8 & 83 \\
6. & Meropenem & 14 & 23 & 181 & 6.4 & 10.6 & 83 \\
7. & Linezolid & 2 & 20 & 196 & 0.9 & 9.2 & 89.9 \\
8. & Vancomycin & 0 & 19 & 199 & 0 & 8.7 & 91.3 \\
9. & Chloramphenicol & 5 & 15 & 198 & 2.3 & 7.3 & 90.4 \\
10. & Rifampicin & 3 & 14 & 201 & 1.4 & 6.4 & 92.2 \\
11. & Teicoplanin & 8 & 11 & 199 & 3.7 & 5 & 91.3 \\
\hline
\end{tabular}

Table 6 Resistant Drugs for UTI

\begin{tabular}{llllllll} 
Sr. No. & Drugs & \multicolumn{3}{l}{ Profile } & \multicolumn{3}{c}{ \% VALUE } \\
\cline { 3 - 7 } & & $\mathbf{R}$ & $\mathbf{S}$ & $\mathbf{N R}$ & $\mathbf{R}$ & $\mathbf{S}$ & NR \\
1. & Cefotaxime & 40 & 10 & 168 & 18.3 & 4.6 & 77.1 \\
2. & Ciprofloxacin & 38 & 17 & 163 & 17.4 & 7.8 & 74.8 \\
3. & Amoxicillin-clavulanic acid & 37 & 14 & 167 & 17 & 6.4 & 76.6 \\
4. & Cefipime & 31 & 8 & 179 & 14.2 & 3.7 & 82.1 \\
5. & Co-trimoxazole & 29 & 22 & 167 & 13.3 & 10.1 & 76.6 \\
6. & Ticarcillin Clavulanic Acid & 28 & 6 & 184 & 12.8 & 2.8 & 84.4 \\
7. & Cefuroxime & 26 & 11 & 181 & 11.9 & 5 & 83 \\
8. & Aztreonam & 24 & 10 & 184 & 11 & 4.6 & 84.4 \\
9. & Cefazolin & 23 & 10 & 185 & 10.6 & 4.6 & 84.9 \\
10. & Ampicillin & 21 & 2 & 195 & 9.6 & 0.9 & 89.4 \\
11. & Erythromycin & 15 & 12 & 191 & 6.9 & 5.5 & 87.6 \\
12. & Clindamycin & 11 & 8 & 199 & 5 & 3.7 & 91.3 \\
\hline
\end{tabular}

The rest 16 drugs to which bacteria seems resistant (Table 4) were screened again to generate the resistance profile. Table 6 is showing drugs which were resistant to UTI.
Although 16 drugs were showing resistance (Table 4.26) but only those showing resistance $>18 \%$ were considered. Cefotaxime $18.3 \%$ was found most resistance followed by Ciprofloxacin 
17.4\%, Amoxicillin-clavulanic acid 17\%, Cefipime $14.2 \%$.

Overall, the results suggest Amikacin, Nitrofurantoin and Gentamycin as sensitive drugs to UTI among the individuals over the age of 51 in Garhwal region of Uttarakhand.

\section{Discussion}

In the elderly (51 and above) age group of Garhwal region the infection in males $(22.01 \%)$ was higher than females (16.97\%) (Table 1). The reason behind higher infection in male of older age might be their advancing age that leads to enlargement of prostate in males (Vigil, 2016) while in females no such things happens. The enlarged prostate in older males push against the urethra, restricting the urine flow and allowing higher bacterial growth leading to higher chances of UTI (Mobley et al., 2015; Lee and Cuo, 2016). Besides this kidney/ bladder stones, these are more common in ageing males this affects the urine forcing power of the urethra which is one of the main defenses against colonizing bacteria (Schwadrer and Wolfe, 2017).

Amikacin was most sensitive followed by Nitrofurantoin and Gentamycin while Cefotaxime was found most resistance followed by Ciprofloxacin and Cefipime. The increased sensitivity indicate the infection by the newly developed strains having no resistance developing mechanism in the pathogens however; the self-drug abuse practice cannot be overruled prior the sampling for microbiological investigation. The antibiotic resistance moving towards more sensitive age group i.e. 51 years and above who are already having a compromised immunity because of several ailments sometimes and age very often.

Among the Gram Negative bacteria (GNB) E.coli was found to be predominant causing UTI in both male and female individuals. Out of 218 individuals, 20 male and 19 female individuals were found infected by E.coli. The second most common pathogen in GNB wasAcinetobacter sp. 3 male and 1 female were infected by it. In individuals of Gram Positive Cocci, CoNS (Coagulase Negative Staphylococcus) was main causative agent infecting 8 male 4 female and second most common pathogen in GPC was Enterococcus spp. 2 male and 6 females were infected by it. In fungus Candida sp. were isolated in 1 male and in 1 female and Candida albicansisolated from 2 male urine samples.

Antibiotics are the only treatment available to cure any infection of living beings and are necessary for the treatment of UTIs, but resistance to antibiotics has been reported globally, specifically in developing countries lead to worries. Chandra et al., 2017(17) were also of the fact that the irrational use of antibiotics is leading to the resistance among the bacteria and hence they emphasize on the need of developing novel plant based antibiotics.

Thus, while the prevalence of UTI is much higher among the elderly individuals (Tsan et 
al., 2010; Cotter et al., 2012), the higher and irrational use of antibiotics have also had severe effects as the bacteria developed resistance against these antibiotics (Zaman et al., 2017).

\section{Conclusions}

As in any parts of world, the UTI is highly prevalent among elderly population of Garhwal region also. The overuse of antibiotics has added to the problem rather solving it. This study provides a baseline data for the UTI sensitive elderly population of Garhwal region. This will also help the state health department in making strategies to contain the infection among elderly people which sometimes becomes lifethreatening in the remote hilly areas of this region. Thus, it is suggested to prevent the over and irrational use of antibiotics, while there is a need of creating awareness among the elderly individuals about sanitization. The rate of infection is higher among the male individuals as compared their female counterpart, thus they need a higher care.

\section{References}

Angus DC, Linde-Zwirble WT, Lidicker J, Clermont G, Carcillo J, Pinsky MR. (2001). Epidemiology of severe sepsis in the United States: analysis of incidence, outcome, and associated costs of care. Read Online: Critical Care Medicine| Society of Critical Care Medicine. ; 29 (7):1303-10
Barnett B J, Stephens D S (1997). Urinary tract infection: an overview. The American journal of the medical sciences, 314(4), 245-249.

Chandra H, Bishnoi P, Yadav A, Patni B, Mishra A P, Nautiyal A R (2017). Antimicrobial resistance and the alternative resources with special emphasis on plantbased antimicrobials-a review. Plants, 6(2), 16.

Cotter M, Donlon S, Roche F, Byrne H, Fitzpatrick F (2012). Healthcare-associated infection in Irish long-term care facilities: results from the First National Prevalence Study. Journal of Hospital Infection, 80(3), 212-216.

Crnich CJ, Jump R L, Nace D A (2017). Improving management of urinary tract infections in older adults: A paradigm shift or therapeutic nihilism?.

Farzana R, Shamsuzzaman S M, Mamun K Z, Shears P (2013). Antimicrobial susceptibility pattern of extended spectrum (beta-lactamase producing Gram- negative bacteria isolated from wound and urine in a tertiary care hospital , Dhaka city. Bangladesh. Southeast Asian Journal of Tropical Medicine \& Public Health, 44(1), 96-103.

Gharbi M, Drysdale J H, Lishman H, Goudie R, Molokhia M, Johnson A, Aylin P (2019). Antibiotic management of urinary tract infection in elderly patients in primary care 
and its association with bloodstream infections and all cause mortality: population based cohort study. bmj, 364 .

Jamil I, Zafar A, Qamar M U, Ejaz H, Akhtar J, Waheed A (2014). Multi-drug resistant Klebsiella pneumoniae causing urinary tract infections in children in Pakistan. African Journal of Microbiology Research, 8(4), 316-319.

Lee C L, Kuo H C (2016). Videourodynamic analysis in men with lower urinary tract symptoms: Correlation between age and prostate size with lower urinary tract dysfunction. Urological science, 27(1), 2125 .

Manikandan S, Ganesapandian S, Singh M, Kumaraguru A K (2011). Emerging of multidrug resistance human pathogens from urinary tract infections. Curr. Res. Bacteriol, 4(1), 9-15.

Mobley, D., Feibus, A., \& Baum, N. (2015). Benign prostatic hyperplasia and urinary symptoms: evaluation and treatment. Postgraduate medicine, 127(3), 301-307.

Mody, L., \& Juthani-Mehta, M. (2014). Urinary tract infections in older women: a clinical review. Jama, 311(8), 844-854.

Nace DA, Drink PJ, Crnich C J (2014). Clinical uncertainties in the approach to long term care residents with possible urinary tract infection. Journal of the American Medical Directors Association, 15(2), 133-139.
PHE English surveillance programme for antimicrobial utilisation and resistance (ESPAUR) Report 2016. Public Health England, 181.

Rowe T A, Juthani-Mehta M. (2013). Urinary tract infection in older adults. Aging health, 9(5), 519-528.

Semwal A C, Saklani P, Mathuria Y P (2017). Urinary tract infection among children and adolescents of Garhwal Region of Uttarakhand, India. African Journal of Microbiology Research,11(36), 13921398.

Tsan L, Langberg R, Davis C, Phillips Y, Pierce J, Hojlo C, ...Roselle, G. (2010). Nursing home-associated infections in Department of Veterans Affairs community living centers. American journal of infection control, 38(6), 461-466.

Vigil Humberto R., and Duane R. Hickling. "Urinary tract infection in the neurogenic bladder." Translational andrology and urology 5, no. 1 (2016): 72.

Zaman SB, Hossain N, Khandker S. Impact of improved cooking stove on maternal health in rural Bangladesh: A quasi-experimental study. Journal of Medical Research and Innovation. 2017 Jun 10;1(3):1-9. 